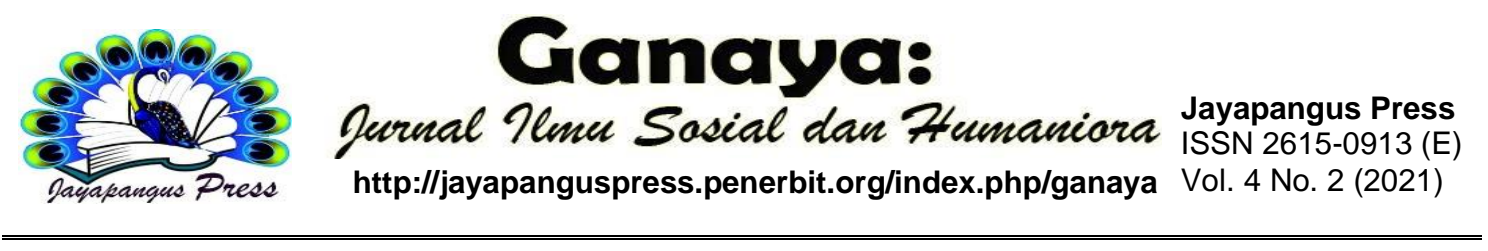

\title{
Faktor Menonton Drama Korea Melalui Media Online (Web) Pada Remaja Putri
}

\author{
Talitha Reyhan Widana1, Diajeng Herika Hermanu² \\ ${ }^{1}$ Broadcasting, STIKOM InterStudi, Jakarta \\ ${ }^{2}$ Communication, STIKOM InterStudi, Jakarta \\ 1'talitchawdn@gmail.com²adjengq@gmail.com
}

\begin{tabular}{l}
\hline Keywords: \\
\hline Korean Wave, \\
Korean Drama, \\
Learning, Online \\
Media, \\
Sociability \\
\hline
\end{tabular}

Abstract
This study aims to identify the factors of watching Korean
dramas through online media (web) in young women. The study
was conducted by distributing 400 questionnaires to young
women in DKI Jakarta through an online survey. Quantitative
data analysis methods are used and analyzed through factor
analysis. The factor analysis summarizes two factors of watching
Korean dramas, namely the learning factor and the sociability
factor. It was found that Learning and Sociability are factors that
influence young women to watch Korean dramas through online
media (web) be-cause of the easy internet access and complete
streaming facilities.

Kata Kunci:

Abstrak
Penelitian ini bertujuan mengidentifikasi faktor menonton
drama Korea melalui media online (web) pada remaja putri.
Penelitian dilakukan dengan membagikan 400 kuesioner kepada
remaja putri di DKI Jakarta melalui survei online. Metode
analisis data kuantitatif digunakan dan diana-lisis melalui
analisis faktor. Analisis faktor meringkas dua faktor menonton
drama Korea yaitu faktor Learning, dan faktor Sociability.
Ditemukan bahwa Learning dan Sociability adalah faktor-faktor
yang memang mempengaruhi para remaja putri untuk menonton
drama Korea melalui media online (web) karena mudahnya
akses internet serta lengkapnya fasilitas streaming.

\section{Pendahuluan}

Dalam era globalisasi saat ini kemajuan pada bidang teknologi maupun komunikasi kini memungkinkan manusia di seluruh dunia untuk dapat saling bertukar informasi atau berkomunikasi dengan satu sama lain. Hampir tidak ada batas untuk masyarakat melakukan pertukaran informasi antar bangsa di berbagai belahan dunia (Aw, 2010). Globalisasi dalam bentuk komunikasi antar budaya juga mulai tumbuh seiring 
dengan adanya interaksi sosial yang ditimbulkan, sehingga melibatkan nilai-nilai sosiokultural individu maupun kelompok yang melintasi batas komunikasi untuk berhubungan dengan individu maupun kelompok lainnya. Interaksi antarbudaya di suatu wilayah juga menjadi gencar dengan ter-bukanya arus globalisasi yang kini memudahkan manusia untuk saling berkomunikasi. Perkembangan teknologi juga menyebabkan peningkatan interaksi antarbudaya ini menjadi lebih memiliki kualitas dan kuantitas (Nasution, 2018).

Saat ini sudah lebih dari satu dek-ade sejak beredar dan meluasnya budaya popular Korea kedalam Asia Timur, dan telah meluas ke negara Asia lainnya. Budaya popular Korea adalah produk budaya yang diproduksi secara massa seperti musik K-Pop, drama Korea, dan film Korea (Tuk, 2012). Hallyu atau Korean wave menjadi istilah yang digunakan untuk penyebaran budaya pop negara Korea Selatan yang terjadi secara mendunia di berbagai belahan negara di dunia, termasuk salah satunya di Indonesia (Shim, 2006).

Perkembangan di bidang teknologi dan informasi telah berhasil membawa perubahan yang besar pada penyebaran Korean wave. Jika sebelumnya Hallyu atau Korean wave menyebar hanya dengan melalui media konvensional saja, seperti televisi, majalah, dan radio, sejak terjadinya perkembangan di bidang teknologi dan informasi, yang juga pada akhirnya membawa perubahan terhadap bentuk media dan memunculkan media baru, sehingga penyebaran Korean wave juga mengalami adanya perubahan. Produk budaya ini dipromosikan, didistri-busikan, dan dikonsumsi melalui new media oleh seluruh industri hiburan dan para penggemarnya (Kuwahara, 2014).

Menurut Arango pada tahun 2016, saat ini, banyak situs Web yang menye-diakan layanan streaming online dengan adanya subtitle serta munculnya forum dan papan pesan yang memungkinkan komunitas online untuk berdiskusi mengenai budaya Korea. Misalnya, Dramafever adalah salah satu situs yang memungkinkan pemirsa untuk dapat menonton drama Korea secara gratis dan juga pemirsa dapat menulis ulasan dan menilai drama favorit mereka di situs (Web) tersebut, dengan adanya media online tersebut pemirsa merasa dimu-dahkan untuk menonton Drama Korea yang diinginkan (Arango, 2016). Selain dorongan perkembangan new media, Faktor Learning juga menjadi alasan meledaknya penyebaran budaya Korea di Indonesia, pasalnya hal tersebut telah mendorong minat orang-orang, teru-tama remaja, untuk mempelajari Bahasa Korea, melalui musik pop Korea, drama Korea, bahkan film Korea dapat menjadi salah satu cara yang paling menyenangkan untuk menyerap budaya dan Bahasa Korea (Sulastri \& Hasby, 
2017). Selain itu, dengan berkembangnya perusahaan besar Korea di Indonesia membuat Bahasa Korea menjadi Bahasa yang banyak diperhitungkan (Lestari, 2010). Selain Bahasa, setiap drama pasti memiliki adegan mengkonsumsi makanan khas Korea seperti kimchi, bulgogi , ramyun dan ja-jangmyeon yang membuat penonton tertarik dengan kuliner khas Korea, selain itu dari menyaksikan drama Korea tanpa sadar penonton akan mengetahui kebiasaan dan budaya orang Korea (Hipwee, 2017) . Sehingga, tanpa sadar rasa ingin tahu penonton terhadap sejarah Korea muncul saat menonton drama Korea, salah satunya Scarlet Heart Ryeo yang dapat membuat penonton sampai mencari tahu masamasa Kerajaan di Korea, dari masa dinasti Goryeo hingga masa dinasti Joseon, dan bagaimana kisah rajanya (Hipwee, 2017) .

Selain itu, penonton K-Drama baik secara sadar maupun tidak, akan mengenal beberapa budaya serta kebiasaan orang Korea secara otodidak. Adapun hal-hal yang ditonjolkan seperti, memberi hormat dengan cara membungkuk, makanan khas Korea, melakukan apresiasi seni dalam keseharian (dalam hal budaya Korea), minum minuman beralkohol, mengenal pakaian tradisional Korea (hanbok), hingga mengenal tulisan Korea (hangul) bahkan mempelajarinya (I. P. Putri et al., 2019). Melihat tayangan drama Korea selain dapat menjadi hiburan bagi remaja, dapat menambah pengetahuan mengenai pem-belajaran Bahasa Korea, budaya Korea, dan berbagai hal yang tidak bisa didapatkan di Indonesia, dan dapat memberikan sebuah motivasi dari karakter atau tokoh peran yang ada dalam drama atau film Korea maupun perjuangan kehidupan nyata idol Korea (Kaparang, 2013). Tidak hanya dari Faktor Learning, Faktor Sociability juga membuat remaja gemar menonton drama Korea agar dapat menambah intensitas bersosialisasi dengan teman dan keluarga, berdiskusi dengan teman-teman dan memiliki topik percakapan yang sama dengan teman dan keluarga mengenai drama Korea (Ama-ran, 2018).

Drama korea memiliki berbagai macam genre dan dengan beragamnya genre tersebut dapat memberikan banyak dampak, salah satunya adalah dampak positif, sesuai dengan Faktor-faktor yang diteliti pada penelitian ini yaitu Faktor Learning dan juga Sociability, dimana dampak positif tersebut seperti memiliki pengetahuan baru, cara mencari teman dan pekerjaan yang diperlihatkan dalam drama Korea, memahami bahasa korea, dan memiliki motivasi untuk mendapat Pendidikan yang bagus. Kebudayaan yang ditampilkan seperti adanya sistem hirearki yaitu menghormati orang yang lebih tua dengan menggunakan bahasa yang sopan dan selalu menghormati orang-orang yang lebih 
muda. Drama korea dengan genre pendidikan banyak diminati oleh sebagian audience karena banyak terdapat informasi seputar pendidikan di Korea Selatan yang tidak bisa didapatkan di Indonesia. Pendidikan di Korea Selatan memang terkenal dengan keketatannya serta betapa keras peserta didik disana untuk belajar demi mendapatkan nilai yang memuaskan dan dapat masuk ke perguruan tinggi yang diinginkan serta jurusan yang memberikan jaminan kerja dengan prestise yang tinggi dalam masyarakat. Maka dari itulah genre pendidikan sangat diminati oleh audience remaja dengan berbagai permasalahan yang ditampilkan di drama Korea. Kemudian, melihat drama korea tidak hanya sekedar hiburan semata, namun dengan melihat drama korea audience juga dapat mempelajari bahasa korea. (Prasanti \& Dewi, 2020)

Remaja suka mengadopsi kosa kata bahasa korea dalam kehidupan sehari- hari. Kata-kata yang sering digunakan yaitu 감사합니다 /고마워(kamsahamnida /gomawo) yang memiliki arti terima kasih. Bahkan sebagian besar dari mereka lancar berbahasa korea tanpa harus membaca terjemahan untuk mengerti artinya.Tak jarang juga merekadapat membaca huruf Hangul atau huruf korea. Secara tidak langsung remaja juga melatih kemampuan linguistic mereka dengan mempelajari bahasa korea secara otodidak. Dengan itu penguasaan bahasa mereka tidak hanya terpaku pada bahasa internasional yaitu bahasa inggris namun, memiliki kemampuan bahasa yang beragam salah satunya adalah bahasa korea. Adanya drama korea juga memberikan motivasi bagi mereka untuk mencoba merasakan pendidikan ke Korea Selatan. Saat ini sudah banyak program pertukaran guru dan tenaga pengajar, pertukaran ahli di bidang primary and secondary education, kerjasama antar universitas/sekolah, recognition degrees, human resources development, pemberian beasiswa, joint research, dan penyelenggaraan berbagai kegiatan seminar/konferensi/pameranyang dibuka akibat kerjasama pemerintah Indonesia dan Korea Selatan akan membuat motivasi untuk menuntut ilmu semakin tinggi. (Angelicha, 2020).

Pada penelitian sebelumnya yang dilakukan oleh Mazdan Ali Amaran, dinyatakan bahwa ada dua faktor yang direkomendasikan dan valid yang membuat remaja tertarik untuk menonton drama Korea, faktor tersebut adalah faktor Learning, dan faktor Sociability. Pada penelitian ini akan diteliti kembali dua faktor tersebut, apakah masih valid pada penelitian kali ini, yaitu faktor Learning, untuk memuaskan kebutuhan mempelajari budaya Korea seperti Bahasa, masakan Korea, fashion, dan juga tujuan wisata terkenal di Korea, dan faktor Sociability, dimana menonton drama Korea 
diharapkan dapat menambah intensitas bersosialisasi dengan teman dan keluarga seperti menghabiskan waktu bersama, memiliki diskusi drama dengan teman-teman dan memiliki topik percakapan umum yang sama dengan teman dan keluarga mengenai drama Korea (Amaran, 2018).

Menurut hasil survey Asosiasi Penyelenggara Jasa Internet Indonesia pada tahun 2019, pengguna Internet terbanyak adalah remaja dengan rentang usia 15-19 tahun (Asosiasi Penyelenggara Jasa Internet Indonesia, 2019), kemudian menurut suvei yang dilakukan oleh Tirto.id preferensi Drama korea di Indonesia didominasi oleh wanita sebesar $85,17 \%$ (Tirto.ID, 2017), Sehingga penelitian ini dilakukan terhadap remaja putri dengan rentang usia tersebut. Faktor yang diidentifikasi dalam penelitian ini adalah tentang pengaruh yang ditemukan dalam teori uses and gratification, menjelaskan bahwa remaja menonton drama Korea untuk memuaskan dan memenuhi kebutuhan mereka akan pembelajaran tentang budaya Korea seperti masakan Korea, trend mode, bahasa dan juga tempat-tempat wisata terkenal di Korea serta untuk bersosialisasi dengan teman dan keluarga, menghabiskan waktu bersama, mendiskusikan drama Korea dengan teman dan memiliki topik pem-bicaraan umum dengan teman dan keluarga.

Pada penelitian sebelumnya yamg dilakukan oleh Mazdan Ali Amaran, menonton drama Korea dikalangan anak muda sangat dipengaruhi oleh faktor Learning dan faktor Sociability, sehingga pada penelitian kali ini, diteliti untuk mengetahui faktor menonton drama korea melalui media online (Web), terhadap remaja putri. Dari mengidentifikasi faktor-faktor menonton Drama Korea pada Remaja, pada penelitian ini adalah remaja putri, apakah memang benar bahwa faktor tersebut mempengaruhi remaja putri di penelitian ini. Tujuan ini diperoleh dengan cara menyelidiki apa hasrat dan kebutuhan yang ingin dipenuhi oleh remaja putri dari menonton drama Korea melalui faktor-faktor tersebut khususnya faktor Learning dan faktor Sociability.

\section{Metode}

Penelitian akan diolah menggunakan metode kuantitatif, yaitu kegiatan untuk menemukan sebuah pengetahuan yang didukung dengan data dalam bentuk angka sebagai alat untuk menganalisis keterangan-keterangan mengenai apa saja yang ingin diketahui atau dibutuhkan (Kasirom, 2010). Penelitian dilakukan dengan bantuan Statistical Package of the Social Sciences (SPSS) versi 24.0 dan Microsoft Excel untuk menganalisis 
hasil yang diperoleh dari kuesioner. Data yang dikumpulkan dianalisis dan menjalani uji reliabilitas untuk menghasilkan nilai alpha Cronbach (Amaran, 2018).

Menurut Suryabrata, reliabilitas akan menunjukkan seberapa jauh hasil pengukuran dengan alat tersebut dapat dipercaya. Hasil pengukuran tersebut dipastikan reliabel dalam artian benar-benar memiliki tingkat konsistensi dan kemantapan yang kuat (Suryabrata, 2014). Menurut George \& Malery, nilai alpha Cronbach yang kurang dari 0,5 tidak dapat diterima, nilai antara 0,5 sampai 0,6 dan 0,6 sampai 0,7 dianggap buruk dan dipertanyakan. Sedangkan kisaran nilai antara 0,7 sampai 0,8 dapat diterima dan kisaran nilai antara 0,8 sampai 0,9 dianggap baik. Terakhir, untuk nilai yang lebih tinggi dari 0,9 adalah nilai yang luar biasa (George \& Mallery, 2010). Semua hasil yang dianalisis disajikan dalam bentuk tabel atau bagan.

Data yang dikumpulkan juga dianalisis melalui analisis faktor untuk mencapai tujuan penelitian mengenai faktor-faktor menonton drama Korea melalui media online diantara remaja putri. Williams, Onsman, \& Brown (Williams et al., 2010) menyatakan bahwa tes Kaiser Meyer Olkin (KMO) mengukur kecukupan pengambilan sampel dan Barlett's test of Sphericity digunakan untuk mengukur apakah data responden sesuai untuk analisis faktor. Agar data sesuai untuk analisis faktor, nilai KMO harus berada di antara kisaran 0,5 sampai 1,0, nilai yang kurang dari 0,5 dinyatakan tidak sesuai untuk analisis faktor. Sebagaimana dikatakan oleh Dennis \& Bocarnea, tes Barlett adalah untuk mengukur kekuatan hubungan antar variabel dalam matriks korelasi (Dennis \& Bocarnea, 2005).

Penelitian dilakukan di seluruh DKI Jakarta, pada bulan juni 2020. Alasan memilih lokasi pelenitian di DKI Jakarta yaitu karena DKI Jakarta merupa-kan ibu kota dan juga kota metropolitan sehingga mudah terkena dampak globalisasi yang salah satunya adalah mudahnya akses menggunakan internet untuk menggunakan media online sebagai media menonton drama Korea. Pengambilan Sampel dilakukan dengan menggunakan metode stratified random sampling, sebagai penelitian yang hanya fokus pada remaja dengan rentang usia 15-19 tahun (Asosiasi Penyelenggara Jasa Internet Indonesia, 2019). Selain itu, metode strat-ified random sampling ini juga digunakan untuk fokus hanya pada mereka yang pernah menonton drama Korea di media online untuk mendapatkan hasil yang lebih akurat. Target populasi dalam penelitian ini adalah penduduk DKI Jakarta usia 15-19 tahun sebesar 418.400 jiwa (Databoks, 2020). 
Selanjutnya, penentuan ukuran sampel dalam penelitian ini menggunakan rumus slovin dengan tingkat toleransi kesalahan sebe-sar 5\% sehingga diperoleh hasil sebagai berikut:

$$
n=\frac{\mathrm{N}}{1+\mathrm{Ne}^{2}}
$$

$\mathrm{N}=418,400:\left(1+\left(418.400 \times 0,05^{2}\right)\right)$

$\mathrm{N}=418,400:(1+(418.400 \times 0,0025))$

$\mathrm{N}=418,400:(1+1.046)$

$\mathrm{N}=418,400: 1.047$

$\mathrm{N}=399,61(400)$

Berdasarkan tingkat toleransi kesalahan sebesar 0,05 (5\%), maka dalam penelitian ini diperoleh hasil sampel atau responden sebanyak 399,61 dan dibulat-kan menjadi 400 wanita usia 15-19 tahun. Sesuai dengan perhitungan sampel menggunakan rumus slovin, kuisioner akan dibagikan kepada 400 responden remaja putri dengan usia 15-19 tahun di DKI Jakarta, serta didistribusikan melalui tautan survei online yang didukung oleh Google Form atau https://docs.google.com. Peneliti akan menjelaskan secara singkat kuesioner untuk memastikan bahwa responden me-mahami urutan kuesioner. Kuesioner beri-si tentang faktor menonton drama Korea melalui media online diantara remaja putri. Selanjutnya, skala likert 6 peringkat digunakan untuk mengidentifikasi faktor menonton drama Korea melalui media online diantara remaja putri serta untuk mengukur pengaruh drama Korea pada pengetahuan dan perilaku sosial remaja putri.

\section{Hasil dan Pembahasan}

\section{Komunikasi dan Perkembangan Media Online}

Saat ini, dunia internasional, termasuk Indonesia, berada pada era yang penuh dengan komunikasi dan teknologi informasi. Kemajuan teknologi telah memberikan sumber informasi dan komunikasi yang dimiliki secara luas oleh umat manusia. Menurut catatan Bucy, komunikasi menggunakan Web terus berkembang. Lalu lintas data komunikasi dari server web meningkat. Situasi ini memberikan ruang baru bagi semua aspek kehidupan manusia. Ini karena web dan aplikasinya adalah lingkungan komunikasi yang dapat digunakan untuk berbagai tujuan. (Bucy, 2002).

Teknologi informasi dan komunikasi ini memunculkan situasi dunia yang sama yang ditempati oleh masyarakat informasi, yaitu desa global. Pada saat yang sama, ada 
tren ekonomi untuk memperluas pasar ke seluruh penjuru dunia. Di era yang disebut globalisasi, sinergi ini telah melahirkan berbagai mode interaktif. Keberadaan Internet dan aplikasi web (sebagian) membuat ketersediaan informasi dalam jumlah besar di dunia yang tak terbayangkan (Bagdikian \& Emeritus, 2004).

\section{Remaja, Drama Korea dan Broadcasting Web Drama}

Korean wave saat ini cukup mempengaruhi dunia, tidak hanya para remaja bahkan orang-orang dewasa pun juga terpengaruhi. Di Indonesia sendiri budaya Korean wave bermula pada awal tahun 2000 yaitu dengan ditayangkannya drama seri Korea di televisi Indonesia. Lewat Korean wave yang melanda, banyak orang yang tertarik untuk kemudian berusaha mempelajari bahasa maupun kebudayaan Korea (Faidol Juddi, 2019) Menurut Briandana dan Ibrahim (Briandana, 2015), budaya populer Korea telah berhasil memperoleh ketenaran yang sangat luas dari Asia Timur ke kawasan Asia Tenggara sejak akhir tahun 1990-an. Salah satu drama seri Winter Sonata adalah salah satu drama seri yang menjadi awal mula industri K-pop di mana budaya populer Korea mulai diakui sebagai sebuah wabah media massa, yang juga dikenal sebagai gelombang Korea atau Korean wave (Hallyu), drama seri tersebut berhasil dengan sangat baik menyajikan makanan khas dan budaya serta daya tarik Suasana Pulau Nami yang menjadikan Korea sebagai salah satu negara yang paling banyak dikunjungi di Asia, dengan begitu, popularitas drama Korea mulai meningkat melalui gelom-bang korea yang kini menyebar ke seluruh dunia (Briandana, 2015).

Menurut Nielsen Consumer and Media View pada tahun 2016, saat ini remaja terutama usia 15 - 19 tahun dapat dengan mudah mengakses serial drama apapun dengan adanya kemajuan teknologi. Menurut survei yang ada, remaja tersebut cenderung mengakses in-ternet dari rumah dan sebagian besar dari mereka menggunakan perangkat mobile terhitung sejak pagi hingga waktu menjelang tidur. Aktivitas penggunaan internet oleh remaja terbesar saat ini adalah untuk berinteraksi melalui social media, mengakses situs pencarian, bermain games online, mengunduh film dan mendengarkan musik (Nielsen, 2016). Untuk ketertarikan menonton, remaja Indonesia dapat menghabiskan satu hingga sedikitnya dua jam per hari (38,78 persen) dan 3 hingga 4 jam (33,08 persen) untuk menonton drama Korea pilihannya. Untuk pilihan waktu menonton, mayoritas remaja Indonesia penggemar drama Korea memilih untuk menonton sebelum 
beristirahat di malam hari (41,06 persen). Ada juga yang menonton nya di akhir pekan atau hari libur (37,26 persen) (Tirto.ID, 2017) .

Sementara untuk mendapatkan drama favoritnya, mayoritas remaja Indonesia mengunduh sendiri drama Korea yang ingin mereka tonton (55,13 persen). Biasanya, mereka mengunduh melalui website penyedia drama yang difasilitasi dengan berbagai macam terjemahan dalam berbagai bahasa. Sementara, sebanyak 35,36 persen remaja lainnya melakukan streaming dari beberapa website seperti Youtube, Viki, dan lainnya (Tirto.ID, 2017). Riset Tirto.id ini menyebut bahwa media sosial, merupakan sumber informasi bagi para remaja milenial penggemar drama Korea menemukan rekomendasi drama yang akan ditonton (55,13 persen). Hanya 2,66 persen yang mendapatkan informasi mengenai tontonan drama Korea dari kerabat dekat. Hal tersebut menunjukkan bahwa penikmat drama Korea di Indonesia lebih menyukai mencari informasi melalui media online dibandingkan mencari tahu melalui kerabat dekat maupun lingkungan sosial lainnya (Tirto.ID, 2017). Dalam survei penelitian sebelumnya oleh Tirto.id, persentase masyarakat Indonesia yang menyukai drama Korea sebesar 80,61 persen, mereka menyatakan bahwa alur cerita yang menarik dan tidak langsung pada intinya adalah alasan utama audiens menonton drama Korea. Drama Korea memang terkenal di Indonesia karena memiliki perbedaan karakteristik dengan sinetron Indonesia yang cenderung panjang dan lebih bertele-tele (Tirto.ID, 2017). Sebagaimana dinyatakan oleh Lu dan Lo, adanya keterhubungan ditemukan menjadi faktor utama yang menarik perhatian penonton. Terhubung nya audiens dengan karakter dan latar yang kontekstual dalam seri drama tertentu berkontribusi terhadap kepuasan audiens terhadap seri drama tertentu (Lu \& Lo, 2007). Namun, menurut Steinkamp menemukan bahwa keterhubungan saja tidak relevan untuk menjadi penentu utama kepuasan audiens karena perasaan audiens tentang keterhubungan dapat dipengaruhi oleh banyak hal. Dengan demikian, Steinkamp mengemukakan bahwa faktor-faktor pemirsa yang menonton drama Korea harus diselidiki dalam perspektif memuaskan kebutuhan mereka seperti mempelajari budaya dan bahasa Korea, memudahkan sosialisasi dengan kerabat maupun keluarga yang memiliki kegemaran yang sama, dan lain sebagainya (Steinkamp, 2010). Namun, penelitian saat ini membahas faktor-faktor yang memotivasi remaja untuk menonton drama Korea dalam perspektif kepuasan yang dicari. Studi ini meneliti keinginan dan kebutuhan yang dicari pemirsa dari menonton drama Korea. 
Penelitian ini menggunakan teori gratifikasi sebagai landasan teori untuk mengembangkan kerangka penelitian (Gambar 1). (Jiang \& Leung, 2012) mengidentifikasi dua poin yang dicari pemirsa dari menonton serial drama yaitu Sociability, dan Learning, berdasarkan teori uses and gratification. Teori uses and gratification adalah pendekatan yang berpusat pada audiens tentang bagaimana pemirsa menggunakan media untuk memenuhi kebutuhan mereka (Jiang \& Leung, 2012). Dua faktor yang diidentifikasi dalam penelitian ini adalah di antara motivasi yang ditemukan dalam teori uses and gratification yang menjelaskan bahwa remaja menonton drama Korea untuk memuaskan kebutuhan mereka akan pembelajaran tentang budaya Korea seperti masakan Korea, mode, bahasa dan juga tujuan wisata terkenal di Korea serta untuk bersosialisasi dengan teman dan keluarga seperti menghabiskan waktu bersama, bergabung dengan diskusi drama dengan teman dan memiliki topik percakapan umum dengan teman dan keluarga. Secara keseluruhan, variabel dependen dalam penelitian ini adalah menonton drama Korea melalui media online pada remaja putri sementara variabel independennya adalah Faktor Learning dan Faktor Sociability (Amaran, 2018)

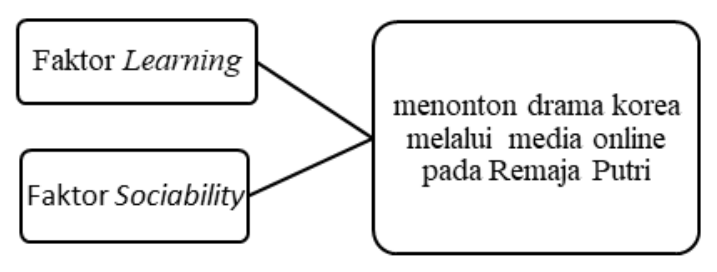

\section{Gambar 1. Model Penelitian}

\section{Hipotesis}

H1: Learning merupakan faktor dari menonton drama korea melalui media online pada remaja putri

H2: Sociability merupakan faktor dari Menonton drama Korea melalu media Online pada remaja putri

Item yang terlibat dalam latar belakang demografi responden adalah kelompok usia, domisili tempat tinggal (dalam lingkup DKI Jakarta), dan beberapa pertanyaan lain yang berhubungan dengan drama Korea seperti frekuensi menonton drama Korea, dan website yang sering digunakan responden untuk menonton drama Korea. 


\begin{tabular}{|l|l|c|c|}
\hline \multicolumn{2}{|l|}{ Latar belakang demografi } & Frekuensi & Persen (\%) \\
\hline Jenis Kelamin & Perempuan & 400 & 100 \\
\hline Usia & 15 & 11 & 2.8 \\
& 16 & 83 & 20.8 \\
& 17 & 88 & 22.0 \\
& 18 & 78 & 19.1 \\
& 19 & 140 & 35.3 \\
\hline Domisili & Jakarta Selatan & 176 & 44.0 \\
& Jakarta Utara & 28 & 7.0 \\
& Jakarta Barat & 73 & 18.3 \\
& Jakarta Timur & 91 & 22.8 \\
& Jakarta Pusat & 27 & 6.8 \\
& Kepulauan Seribu & 5 & 1.2 \\
\hline Website menonton Drakor & VIU & 95 & 23.8 \\
& Netflix & 81 & 20.3 \\
& Drakor.id & 83 & 20.7 \\
& Web Streaming & 114 & 28.5 \\
& Lainnya & 27 & 6.7 \\
\hline & Total & 400 & 100 \\
\hline
\end{tabular}

Gambar 2. Tabel demografi

Tabel menunjukkan bahwa responden dengan usia 15 tahun sebanyak 11 responden $(2,8 \%)$ usia 16 tahun sebanyak 83 responden $(20.8 \%)$, usia 17 tahun sebanyak 88 responden (78\%), usia 18 tahun sebanyak 78 responden (19.1\%), dan usia 19 dengan responden paling banyak yaitu 140 responden (35.3\%). Selanjutnya, untuk domisili Jakarta Selatan memiliki responden paling banyak sebesar 176 responden (44.0\%), Jakarta Utara sebanyak 28 responden (7.0\%), Jakarta Barat sebanyak 73 responden (18.3\%), Jakarta Timur sebanyak 91 responden (22.8\%), Jakarta Pusat sebanyak 27 responden $(6,8 \%)$, Kepulauan seribu sebanyak 5 responden $(1.2 \%)$. Sementara website yang digunakan untuk menonton drama Korea, 95 responden (23.8\%) menggunakan VIU, 81 responden (20.3\%) menggunakan Netflix, 83 responden (20.7\%) menggunakan Drakor.id, 114 responden (28.5\%) menggunakan web streaming lainnya, sementara 27 responden $(6.7 \%)$ menggunakan aplikasi lain.

\section{Frekuensi menonton Drama Korea}

Dari hasil survey dapat dibuktikan bahwa responden yang hanya menonton drama Korea satu kali saja dalam suatu waktu sebanyak 18 responden (4,5\%). 20 responden $(5 \%)$ adalah mereka yang jarang menonton drama Korea. 126 responden (31.5\%) adalah mereka yang terkadang menonton drama Korea. Kemudian, responden yang menonton drama korea sangat sering sebesar 236 responden (59\%) dan ini merupakan persentase tertinggi dari frekuensi menonton drama Korea.

Reliabilitas Analisis

Gambar 3 menunjukkan statistik reliabilitas untuk pertanyaan. Analisis reliabilitas adalah untuk menganalisis pertanyaan-pertanyaan yang berkaitan dengan faktor 
menonton drama Korea di media online pada remaja putri untuk memastikan validitas hasil. Sesuai dengan (Field, 2013), kuesioner dengan Nilai Cronbach's Alpha yang lebih tinggi dari 0,8 dianggap dapat dilanjutkan. Gambar 3 menggambarkan Nilai Cronbach alpha dari 7 item yang diteliti adalah 0,844 . Nilai ini dianggap nilai yang baik dan sesuai (George \& Mallery, 2010).

\section{Reliability Statistics}

\begin{tabular}{r|r}
$\begin{array}{c}\text { Cronbach's } \\
\text { Alpha }\end{array}$ & N of Items \\
\hline .844 & 7 \\
\hline
\end{tabular}

Gambar. 3 Nilai Cronbach Alpha

Faktor Analisis

Analisis faktor bertujuan untuk mengidentifikasi dimensi yang mendorong remaja putri untuk menonton drama korea melalui media online. Gambar menunjukkan hasil analisis faktor dengan hasil KMO sebesar 0,819 sesuai yang dikatakan oleh Williams, Osman, \& Brown bahwa nilai minimal KMO adalah 0,5 (Williams et al., 2010) sehingga nilai KMO yang didapat sudah cocok untuk analisis faktor. Sedangkan Bartlett's test untuk mengukur kekuatan hubungan antara variabel dalam correlation matrix (Dennis \& Bocarnea, 2005).

KMO and Bartlett's Test

\begin{tabular}{lll}
\multicolumn{2}{l}{ Kaiser-Meyer-Olkin Measure of Sampling Adequacy. } & .819 \\
Bartlett's Test of & Approx. Chi-Square & 1247.652 \\
Sphericity & df & 21 \\
& Sig. & .000 \\
\hline
\end{tabular}

Gambar. 4 nilai KMO dan Bartlett's

Gambar 5 menunjukkan hasil analisis faktor dengan faktor awal dan kamunalitas. Faktor awal adalah faktor yang tidak mengalami rotasi dan memiliki pola dimensi yang kurang jelas dan tidak stabil. Kolom kedua dan ketiga pada gambar 5 menunjukkan seberapa besar kontribusi variabel terhadap faktor. Komunalitas adalah varian dalan variabel yang diamati yang diperhitungkan oleh dua faktor yang dipilih. Semakin tinggi nilai komunalitas menunjukkan bahwa varian suatu variabel sangat menjelaskan suatu faktor tertentu atau sebaliknya (Child, 2006). 
Berdasarkan gambar 5, variabel dengan komunalitas tertinggi yaitu memiliki kesamaan topik percakapan dengan teman dan keluarga sebesar 0,807 dan ini menggambarkan bahwa 80,7\% variabel menjelaskan baik faktor 1 maupun faktor 2 . Kemudian dilanjutkan dengan variabel Untuk menyaksikan drama korea bersama teman dan keluarga, dan banyaknya teman yang sering mendiskusikan drama korea dengan nilai komunalitas 0,765 dan 0, 763 masing-masing menunjukkan bahwa 76,5\% dan 76,3\% variabel menjelaskan kedua faktor tersebut.

\begin{tabular}{|l|c|c|c|}
\hline \multicolumn{1}{|c|}{ Komponen awal/ Pernyataan } & \multicolumn{2}{c|}{ komponen } & \multirow{2}{*}{ komunalitas } \\
\cline { 2 - 3 } & faktor1 & faktor2 & \\
\hline $\begin{array}{l}\text { Untuk mempelajari tentang } \\
\text { makanan korea }\end{array}$ & 0,738 & 0,392 & 0,698 \\
\hline $\begin{array}{l}\text { Untuk lebih mengetahui fashion } \\
\text { trend terbaru }\end{array}$ & 0,756 & 0,274 & 0,647 \\
\hline untuk mempelajari bahasa korea & 0,676 & 0,447 & 0,657 \\
\hline $\begin{array}{l}\text { untuk mengetahui lebih banyak } \\
\text { mengenai destinasi wisata }\end{array}$ & 0,687 & 0,407 & 0,638 \\
\hline $\begin{array}{l}\text { Banyaknya teman yang sering } \\
\text { mendiskusikan drama korea }\end{array}$ & 0,760 & $-0,431$ & 0,763 \\
\hline $\begin{array}{l}\text { Agar memiliki topik pembicaraan } \\
\text { dengan teman dan keluarga } \\
\text { mengenai drama korea }\end{array}$ & 0,723 & $-0,533$ & 0,807 \\
\hline $\begin{array}{l}\text { Untuk menyaksikan drama korea } \\
\text { bersama teman dan keluarga }\end{array}$ & 0,705 & $-0,518$ & 0,765 \\
\hline \multicolumn{2}{|l|}{ Before Rotation } \\
\hline $\begin{array}{l}\text { Eigen Values } \\
\text { Original Factors=7 }\end{array}$ & 3.643 & 1.332 & 4.975 \\
\hline \%of variance = Eigen Value/7*100\% & 52.036 & 19.030 & 71.066 \\
\hline
\end{tabular}

\section{Gambar 5 Faktor awal dan Komunalitas}

Faktor 1 menyatakan persentase varian 52\% sedangkan faktor 2 menyatakan 19\% varian dan keduanya menyumbangkan nilai komunalitas sebesar $71 \%$. Karena pola dimensi yang tidak jelas, seperti yang terlihat pada gambar, dengan demikian faktorfaktor membutuhkan untuk menjalani rotasi agar pola dimensi nya lebih stabil. Faktorfaktor tersebut diklasifikasikan menjadi dua dimensi seperti gambar 6 dan 7 yang mempresentasikan bobot faktor dan nilai eigen dari faktor 1 dan faktor 2 setelah rotasi. Empat variabel pertama seperti yang ditunjukkan gambar 6, berkenaan dengan pembelajaran mengenai masakan korea, trend fashion, bahasa korea, dan tempat wisata, menunjukkan perbedaan bobot faktor yang sangat mencolok antara faktor 1 dan faktor 2 , oleh karena itu variabel ini diberi label dalam dimensi Learning. Di sisi lain, tiga variabel lainnya yaitu variabel banyaknya teman yang mendiskusikan drama korea, agar memiliki topik perbincangan dengan teman dan keluarga, dan menonton drama dengan teman dan keluarga masuk kedalam label Sociability.

Faktor 1: Learning (setelah rotasi) untuk mempelajari masakan korea 0,810, untuk mengikuti trend mode terkini 0,744, untuk mempelajari Bahasa korea 0,801, untuk mengetahui tempat wisata 0,782 . Setelah rotasi eigenvalue sebesar $2.622, \%$ of variance 
sebesar 65.547, nilai Alpha Cronbach 0,823, untuk nilai KMO sebesar 0,766, bartlett's test 0,000 .

\begin{tabular}{|l|c|}
\hline Faktor 1: Learning & $\begin{array}{c}\text { After } \\
\text { Rotation }\end{array}$ \\
\hline Untuk mempelajari tentang makanan korea & 0,810 \\
\hline Untuk lebih mengetahui fashion trend terbaru & 0,744 \\
\hline untuk mempelajari bahasa korea & 0,801 \\
\hline untuk mengetahui lebih banyak mengenai destinasi wisata & 0,782 \\
\hline \multicolumn{2}{|c|}{ After Rotation } \\
\hline Eigen Value & 2.622 \\
\hline \% of Variance & 65.547 \\
\hline Cronbach's Alpha value & 0,823 \\
\hline Kaiser-Meyer-Olkin (KMO) & 0,766 \\
\hline Bartlett's Test of Sphericity & 0,000 \\
\hline
\end{tabular}

\section{Gambar 6 Faktor Learning setelah rotasi}

Gambar 6 menunjukkan kumpulan variabel terkait pembelajaran atau Learning dengan empat bobot signifikan setelah rotasi. Hasilnya menunjukkan bahwa variabel yang paling signifikan adalah mempelajari tentang makanan korea dengan bobot tertinggi sebesar 0,810. Kemudian diikuti oleh variabel mempelajari bahasa korea sebesar 0,801, demikian juga mengetahui tempat wisata dan mengikuti trend fashion memberikan kontribusi bobot faktor setelah rotasi masing masing sebesar 0,782 dan 0,744.

\begin{tabular}{|l|c|}
\hline Faktor 1: Sociability & $\begin{array}{c}\text { After } \\
\text { Rotation }\end{array}$ \\
\hline $\begin{array}{l}\text { Banyaknya teman yang sering mendiskusikan } \\
\text { drama korea }\end{array}$ & 0,830 \\
\hline $\begin{array}{l}\text { Agar memiliki topik pembicaraan dengan teman } \\
\text { dan keluarga mengenai drama korea }\end{array}$ & 0,881 \\
\hline $\begin{array}{l}\text { Untuk menyaksikan drama korea bersama teman } \\
\text { dan keluarga }\end{array}$ & 0,857 \\
\hline \multicolumn{1}{|c|}{ After Rotation } \\
\hline Eigen Value & 2.334 \\
\hline$\%$ of Variance & 77.811 \\
\hline Cronbach's Alpha value & 0,857 \\
\hline Kaiser-Meyer-Olkin (KMO) & 0,730 \\
\hline Bartlett's Test of Sphericity & 0,000 \\
\hline
\end{tabular}

Gambar 7 Faktor Sociability setelah rotasi

Gambar 7 menunjukkan variabel yang dikumpulkan terkait faktor kemampuan bersosialisasi atau Sociability dengan 3 bobot faktor setelah rotasi. Hasilnya menunjukkan bahwa memiliki topik percakapan yang sama dengan teman dan keluarga memiliki bobot faktor tertinggi sebesar 0,881 , disusul menyaksikan drama korea Bersama teman dan keluarga, dan banyaknya teman yang mendiskusikan drama korea dengan bobot setelah rotasi masing masing 0,857 dan 0,830. Nilai eigen adalah ukuran varians yang diperhitungkan oleh faktor-faktor sebagai kontribusi faktor (Streiner, 1994). Menurut gambar 6, nilai eigen untuk faktor Learning adalah 2,622 sedangkan untuk Sociability adalah 2,334 seperti yang ditunjukkan pada gambar 6 dan gambar 7. Kedua nilai eigen tersebut lebih tinggi dari nol, hal ini menunjukkan bahwa faktor Learning dan 
Sociability dapat dipertahankan. Persentase varian menunjukkan seberapa besar total varian yang dikontribusikan oleh masing-masing faktor (Yong \& Pearce, 2013). Persentase faktor Learning adalah $65.547 \%$ yaitu lebih rendah dibandingkan dengan persentase varian dari Sociability sebesar 77.811\%. Ini menunjukkan Faktor Sociability tersebut merupakan faktor pendorong terbesar bagi remaja putri untuk menonton drama Korea pada media online web dibandingkan dengan faktor Learning secara keseluruhan. Selain itu, ada sekitar $71 \%$ varian kumulatif yang dapat menjelaskan dengan baik dimensi faktor Learning dan Sociability.

Selanjutnya nilai Cronbach's alpha yang ditunjukkan pada faktor Sociability lebih tinggi dari faktor Learning masing-masing sebesar 0,857 dan 0,823. Hal ini menggambarkan faktor Sociability memiliki stabilitas dan konsistensi data yang lebih tinggi dibandingkan dengan faktor Learning. Nilai KMO untuk faktor Learning sebesar 0,766 lebih tinggi dari nilai faktor Sociability dengan nilai KMO 0,730. Hal ini menunjukkan bahwa faktor Learning memiliki kecukupan sampling yang lebih tinggi dibandingkan dengan faktor Sociability. Selain itu, kedua nilai KMO tersebut lebih tinggi dari 0,50 yang mana menunjukkan bahwa keduanya cocok untuk analisis faktor (Williams et al., 2010). Selain itu, kedua hasil uji bartlett's menunjukkan nilai signifikan yaitu 0,000. Jadi, ini menunjukkan bahwa matriks korelasi adalah matriks identitas dengan semua elemen diagonal sama dengan 1 seperti yang ditunjukkan pada gambar 8 .

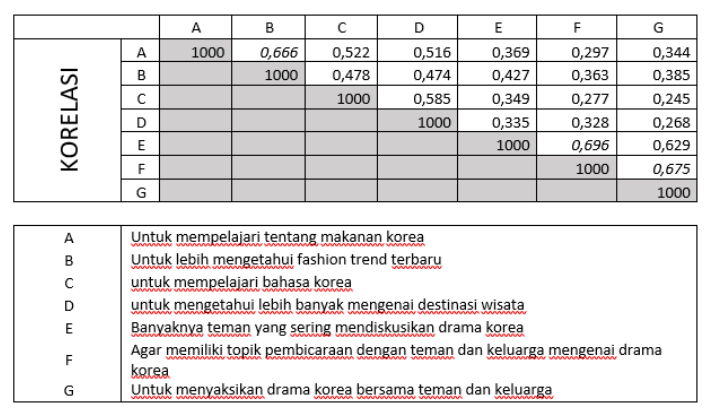

Gambar 8 Matriks Korelasi

Gambar 8 menunjukkan matriks korelasi antar variabel. Variabel mempelajari makanan Korea sangat berkorelasi dengan mengetahui trend fashion terbaru $(0,666)$. Sejalan dengan itu, variabel topik percakapan dengan teman dan keluarga juga sangat berkorelasi yang tinggi dengan banyaknya teman yang mendiskusikan drama Korea $(0,696)$. Untuk menonton drama Korea dengan teman dan keluarga juga sangat berkorelasi dengan memiliki topik pembicaraan dengan teman dan keluarga mengenai drama Korea $(0,675)$. Sesuai dengan pedoman interpretasi koefisien korelasi nilai 0,60- 
0,799 terbilang kuat, sehingga semua korelasi antar variabel diatas terbilang kuat (Sugiyono, 2007).

Ada dua faktor remaja menonton drama Korea yang diidentifikasi dalam penelitian ini yaitu Learning dan Sociability setelah analisis faktor. Pada penelitian sebelumnya telah di identifikasi beberapa kategorisasi motivasi menonton seperti entertainment, relaxation, Learning, arrousal, passing time, diversion, escape, dan Sociability (Rubin et al., 2009). Selain itu, (Jiang \& Leung, 2012) juga mengidentifikasi empat gratifikasi yang dicari penonton untuk menonton serial drama yang mencakup entertainment, Sociability, Learning dan escape, berbasis teori uses and gratification. Teori uses and gratification berpusat pada pendekatan audiens tentang bagaimana menggunakan media untuk memenuhi kebutuhan kognitif dan afektif mereka (Jiang \& Leung, 2012). Dua faktor yang diidentifikasi dalam penelitian ini adalah motivasi yang ditemukan dalam teori uses and gratification yang menjelaskan bahwa remaja putri menonton drama Korea melalui media online web untuk mendapatkan kepuasan dan kebutuhan mereka untuk mempelajari tentang budaya Korea seperti masakan Korea, fashion, bahasa dan juga destinasi wisata terkenal di Korea juga untuk bersosialisasi dengan teman dan keluarga seperti menghabiskan waktu bersama, bergabung dalam diskusi mengenai drama Korea dengan teman-teman dan menonton Bersama dengan teman dan keluarga.

Faktor utama yang memotivasi remaja untuk menonton drama Korea secara keseluruhan adalah faktor Sociability. Sedikit dari mereka yang menonton drama korea hanya karena banyaknya teman teman yang sering mendiskusikan drama Korea, mereka cenderung menonton drama Korea agar mereka dapat mendiskusikannya Bersama teman dan keluarga. Remaja cenderung tergoda untuk menonton drama Korea untuk berinteraksi dengan orang lain karena mereka dapat berkomunikasi dengan menonton bersama atau dengan membicarakan drama yang mereka saksikan. Hal ini secara tidak langsung dijadikan alasan, memiliki topik pembicaraan yang sama dengan teman dan keluarga sebagai tujuan utama menonton drama Korea tertentu yang bisa mereka diskusikan tentang plot yang menarik dari serial drama favorit tertentu itu satu sama lain. Alasan penting berikutnya adalah, para remaja putri sangat menyukai menyaksikan drama Korea bersama teman dan keluarga karena dinilai lebih menyenangkan.

Sejalan dengan itu, Learning ternyata menjadi faktor minor yang mendorong remaja putri untuk menonton drama Korea. Studi tersebut menemukan bahwa remaja 
cenderung menonton drama Korea untuk belajar lebih banyak tentang makanan Korea diikuti dengan mempelajari tentang bahasa Korea serta mengetahui tentang destinasi wisata. Selain itu, pada penelitian ini remaja putri ditemukan cenderung paling tertarik dengan destinasi wisata dibandingkan dengan fashion trend, sebagaimana hasil penelitian sebelumnya. Ditemukan juga bahwa remaja putri menonton drama Korea agar dapat menyaksikan drama Korea Bersama teman dan keluarga dibandingkan dengan banyaknya teman yang sering mendiskusikan drama Korea, atau singkatnya pada penelitian terdahulu remaja merasa bahwa menonton drama sendiri bukanlah sebuah masalah besar, sedangkan pada penelitian kali ini remaja putri lebih memilih menonton drama Korea bersama karena lebih asik dan menyenangkan.

\section{Kesimpulan}

Berdasarkan hasil penelitian, terbukti bahwa Learning dan Sociability adalah faktor-faktor yang mendorong remaja putri untuk menyaksikan drama Korea dan 93,3\% remaja putri memilih menyaksikan drama Korea melalui media online (web) karena mudahnya akses internet di kota besar dan tersedianya subtitle dalam berbagai bahasa yang dapat diunduh dengan mudah maupun disaksikan secara langsung (streaming).

Keinginan para remaja putri untuk dapat bersosialisasi dengan baik didalam lingkup sosial mereka yang dirasa memiliki kegemaran atau ketertarikan yang sama, yaitu mengenai drama Korea membuat Sociablity menjadi faktor utama yang mempengaruhi remaja putri menonton drama Korea, dan Learning menjadi faktor selanjutnya yang mempengaruhi para remaja putri menonton drama Korea agar mereka dapat mempelajari budaya, bahasa, trend fashion, makanan, serta tempat wisata menarik dari negara Korea.

\section{Daftar Pustaka}

Amaran, M. A. (2018). Factors of watching Korean Drama Among Youth in Kuching City, Malaysia. www.ijac.org.uk

Amaran, M. A. (2018). Factors of watching Korean Drama Among Youth in Kuching City, Malaysia. www.ijac.org.uk

Arango. (2016). Like Newspapers, Cable TV Seeks to Profit on the Web - The New York Times. https://www.nytimes.com/2009/06/24/business/media/24pay.html Asosiasi Penyelenggara Jasa Internet Indonesia. (2019). Hasil Survey Penetrasi dan Perilaku Pengguna Internet Indonesia tahun 2018. 
https://www.apjii.or.id/content/read/39/410/hasil-survei-penetrasi-dan-perilakupengguna-internet-indonesia-2018

Aw, S. (2010). Komunikasi Sosial Budaya. Graha Ilmu.

Bagdikian, B. H., \& Emeritus, D. (2004). The New Media Monopoly. Beacon Press.

Briandana, R. (2015). Intercultural Responses To Korean TV Drama Series on Part of University Student in Indonesia [BOOK].

Bucy, E. . (2002). Living In The Information Age: A New Media Reader. Wadsworth Thomson Learning.

Child, D. (2006). The Essentials of Factor Analysis 3rd Edition (3rd editio). Bloomsbury Academic.

Databoks. (2020). Proyeksi Jumlah Penduduk DKI Jakarta 2020 | Databoks. https://databoks.katadata.co.id/datapublish/2019/12/07/jumlah-penduduk-dkijakarta-2020\#

Dennis, R. S., \& Bocarnea, M. (2005). Development of the servant leadership assessment instrument. Leadership \& Organization Development Journal. https://doi.org/10.1108/01437730510633692

Faidol Juddi, M. (2019). Komunikasi Budaya dan Dokumentasi Kontemporer - Moh Faidol Juddi - Google Buku. https://books.google.co.id/books/about/KOMUNIKASI_BUDAYA_DAN_DOK UMENTASI_KONTEM.html?id=EbmcDwAAQBAJ\&redir_esc=y

Field, A. (2013). Discovering statistics using IBM SPSS statistics. Statistics, 58.

George, D., \& Mallery, P. (viaf)92115668. (2010). SPSS for Windows step by step : a simple guide and reference, 17.0 update (10th ed.) [BOOK]. Boston: Allyn \& Bacon. http://lib.ugent.be/catalog/rug01:001424067

Jiang, Q., \& Leung, L. (2012). Lifestyles, gratifications sought, and narrative appeal: American and Korean TV drama viewing among Internet users in urban China. International Communication

Gazette. https://doi.org/10.1177/1748048511432601

Kasirom, M. (2010). Metodologi Penelitian Kuantitatif-Kualitatif. In Malang: UIN Maliki Press.

Kuwahara, Y. (2014). The Korean Wave: Korean Popular Culture in Global Context (Y. Kuwahara (ed.); 1 st ed.). Palgrave Macmillan US. https://doi.org/10.1057/9781137350282 
Lu, X., \& Lo, H. P. (2007). Television audience satisfaction: Antecedents and consequences. Journal of Advertising Research, 47(3), 354-363. https://doi.org/10.2501/S0021849907070365

Nasution, R. D. (2018). Pengaruh Modernisasi dan Globalisasi terhadap Perubahan Sosial Budaya di Indonesia. Jurnal Kominfo, 1-14.

Nielsen. (2016). Gen Z: Konsumen Potensial Masa Depan. https://www.nielsen.com/id/en/press-releases/2016/gen-z-konsumen-potensialmasa-depan/

Rubin, R. B., Rubin, A. M., Graham, E. E., Perse, E. M., \& Seibold, D. (2009). Communication Research Measures II : A Sourcebook (1st Editio). Routledge. https://doi.org/https://doi.org/10.4324/9780203871539

Shim, D. (2006). Hybridity and the Rise of Korean Popular Culture in Asia [JOUR]. Media Culture \& Society - MEDIA CULT SOC, 28, 25-44. https://doi.org/10.1177/0163443706059278

Steinkamp, C. (2010). Internet television use: Motivations and preferences for watching television online among college students Internet Television 1 College of Liberal Arts Internet Television Use: Motivations and Preferences for Watching Television. http://scholarworks.rit.edu/theses

Streiner, D. L. (1994). Figuring out factors: The use and misuse of factor analysis. Canadian Journal of Psychiatry, 39(3), 135-140. https://doi.org/10.1177/070674379403900303

Sugiyono. (2007). Metode Penelitian Kuantitatif Kualitatif dan R\&D. Alfabeta.

Suryabrata, S. (2014). Metodologi Penelitian Cetakan ke 25. PT Raja Grafindo Persada.

Tirto.ID. (2017). Drama Korea Hidup Saya. https://tirto.id/drama-korea-hidup-saya$\mathrm{cmbE}$

Tuk, W. (2012). The Korean Wave: Who are behind the success of Korean popular culture?

Williams, B., Onsman, A., \& Brown, T. (2010). Australian paramedic graduate attributes: A pilot study using exploratory factor analysis [JOUR]. Emergency Medicine Journal : EMJ, 27, 794-799. https://doi.org/10.1136/emj.2010.091751

Yong, A. G., \& Pearce, S. (2013). A Beginner's Guide to Factor Analysis: Focusing on Exploratory Factor Analysis. Tutorials in Quantitative Methods for Psychology, Vol. 9(2), 79-94. https://doi.org/10.20982/tqmp.09.2.p079 
T. Angelicha (2020). Dampak Kegemaran Menonton Tayangan Dram Korea Terhadap Perilaku Remaja. EduPsyCouns: Journal of Education, Psychology and Counseling, Vol. 2, 154-159.

R. Prasanti., \& A. Dewi. (2020). Dampak Drama Korea (Korean Wave) terhadap Pendidikan Remaja. Jurnal Pendidikan, Vol.11 No. 2, Agustus 2020. 